\title{
BREEDING THE CONGO PEACOCK
}

\author{
by \\ A. C. V. VAN BEMMEL \\ Stichting Koninklijke Rotterdamse Diergaarde, Rotterdam
}

\section{HISTORY AND MATERIAL}

The discovery of the Congo Peacock (Afropavo congensis Chapin) is one of the most recent in ornithology. Certainly it is the most famous one. The history of the discovery has been described by CHAPIN in detail $(5,6)$.

The first living specimens exported from Kongo reached the United States June 1949. Charles CorDIER told the story of this remarkable transport and of the painstaking work which he undertook to secure these first specimens $(7,8)$.

Living Congo Peacocks reached Europe 1957. Again it was Charles Cordier who secured these birds, this time for the Royal Zoological Society (Koninklijke Maatschappij voor Dierkunde) at Antwerpen. In the year 1959 not less than three pairs reached Antwerpen again, followed by three males and four females in 1960 (12).

The Royal Zoological Society at Antwerpen, considering that the first aim should be trying to breed these rare birds in captivity, decided to spread the risks of keeping all the birds in one place. So one pair was send to Mr. Jean Delacours famous park at Clères and one pair to the Royal Zoological Garden at Rotterdam. The birds which were obtained in 1960 partly stayed at Antwerpen, partly went to the other park of the Antwerp Society, Planckendael. A single male at the Zoological Garden Kopenhagen and at the Zoological Garden Frankfort, completed, together with some single males in the United States, the whole stock of Congo Peacock outside Kongo.

\section{BREEDING RESULTS WITH CONGO PEACOCK}

The first results with breeding Congo Peacock in captivity were obtained in Kongo by Mr. T. Herrurng 1938. A note on this breeding case, strangely enough a trio in which one of the hens laid three eggs from which after an incubation period of 26 days one chick hatched, has been given by Chapin (4). This first and only chick died however after four days.

The Royal Rotterdam Zoological Garden had the good luck to be the first European Zoo to obtain eggs from the Congo Peacock and to raise the first chick in captivity. Some months later fertile eggs were obtained from one pair at Planckendael. After artificially incubating of 8 days, the only egg left was given to a Bantam hen. It developed normally, but unfortunately was destroyed by unknown cause only a few days before hatching, containing a well developed chick (12).

These results proved the possibility to breed and raise Congo Peacock in captivity, not only under tropical conditions as in the case of Mr. Herruing or under artificially tropical conditions as in Rotterdam, but also under the conditions of a temperate climate as in Planckendael.

\section{THE BREEDING IN ROTTERDAM}

The breeding pair arrived directly from Kongo at Antwerpen, September 1959. They were brought to the Rotterdam Zoo at the 8th of October 1959. The pair was housed in a large aviary in the Tropical house of the Garden. The temperature in this hothouse lies between 22 and $24^{\circ} \mathrm{C}$. Humidity is very high, necessary to keep the collection of tropical plants in good condition.

This seemed to be the right environment, Congo Peacocks being birds of the hot tropical rainforest. The aviary had been planted with Ficustrees and some old willow stubs had been put in for decoration. As we learned from literature that the birds prefer thick undergrowth of the forest, part of the cage had been planted with conifers which offered plenty of cover. This proved to be the right thing. The birds took to the cover at once and only seldom showed 
themselves during daytime. On the other hand they seemed to be hardly disturbed by groups of visitors in the Tropical House. They stepped out from cover only to feed, sat on some low branches in the cover for hours and flew up to the willow stubs to roost during the night. The birds were very slow, even lazy, which made us rather nervous, because we suspected them of being not well. But as they ate their food well, at the end of some weeks we accepted this behaviour as normal.

The food consisted of a mixed diet of grains, fruit, Universeel Sluis, ants pupae and mealworms.

April 1960 the behaviour of the birds changed. They came out from the cover also during daytime, flew up to the willow stubs and showed a most interesting sexual display. Both cock and hen bowed their head deeply, neck, back and spread-out tail at an angle of $45^{\circ}$ with water-level. Much of this display remembered of those of the Peacock Pheasants. Copulation was not observed, but later we found that the hen presented herself pressed flatly to the ground.

Rather unexpected we found on May 10th, 1960 a broken egg lying under one of the willow stubs. We suspected one of the smaller birds in the aviary being the cause of this damage. But we found another egg in the same place the next morning. Now all of a sudden the real cause became clear! The hen had laid her eggs up in the willow trunk, 3 feet over the floor of the cage. The eggs had tumbled down, because the trunk did not offer any nold. This could be an indication that Congo Peacock breed in trees. Nevertheless, the specimen of Mr. Herrling bred on the floor and the eggs at Planckendael also were laid on the floor. I am inclined to believe however that tree-breeding is the normal way.

To prevent further accidents with the precious eggs, we made a sort of nest in the willow trunk, using a flat basket as base. On the 1st of June we found a new egg in this artificial nest. On the $2 d$ of June a second egg was laid and from that moment on the hen hardly ever left the nest. She came down in the late evening to feed and drink. Apart of this short period she stayed on the nest, pressed flat to it and sitting absolutely motionless. By sheer chance we saw June 7 th that there were three eggs in the nest. The hen continued incubating sitting motionless, the eyes closed and in such a position that the keeper once thought that she had died. We were deeply disappointed finding on June 16th that the whole clutch had been broken. This was more disappointing because all three eggs proved to contain a half developed chick! The reason of this misfortune still seems a mystery.
The only thing we could do was to reinforce the base of the nest and remove the few birds which still lived with the Congo Peacocks in the aviary, excepted one small African Lark. After some weeks the birds showed sexual display once more and July $22 \mathrm{~d}$ again an egg was laid. July $23 \mathrm{~d}$ a second egg followed, July 25 th a third one. The hen started incubating that same day. August $22 \mathrm{~d}$ the hen seemed restless, raised herself a little from the nest and sat down again. On the morning of August 23d two nice chicks sat on the edge of the nest, mounting to their mothers back time to time. Soon one of this chicks tumbled down, just for the bill of its father, who had been sitting in the neighbourhood of the nest for the whole time of incubation. The cock immediately took to this chick, and, chuckling in a high pitched voice, brought it to the cover of the conifers. After some minutes the chick vamshed under the breastfeathers of the cock.

So the observation mentioned by previous authors that the cock takes care of the chicks was confirmed. The next day the other chick had come down also. Now both parents took care of the chicks, taking them under the feathers, putting food before them or letting them pick from their bills. The third egg proved to contain a half developed embryo. This egg has been mentioned as infertile by mistake in a previous publication (10). So far the observations by Herrling, and the notes of Chapin and Delacour were confirmed $(4,9)$.

If a stranger comes near the chicks, the cock displays fiercely and even attacks. The chicks grew well, the wings developing rapidly. After three days they flew up to branches one feet over the floor. Within a week they flew up to the willow stubs and spent the night on these, covered mostly by the hen. It showed that one chick developed better than the other one. September 9th we found this dead. Postmortem examination proved that it had fell a victim to coccidiosis. Both the other chick and the old birds proved to be infected also and we treated them with sulfametizine, disinfecting the floor of the cage with Halamid. The birds stayed in good condition and the chick grew up in a normal way. The shoulderfeathers of the chick showed after fourteen days. The immature bird is mottled cinnamon, black and greyish. Soon a slight green gloss appears and gradually this immature dress changed in the full dress of the mature hen, our chick proving itself to be a female. At an age of six months the full mature dress had been attained, only the bare, coppery-red patches on the sides of the neck had not yet developed.

A further description of the downy chick and the 


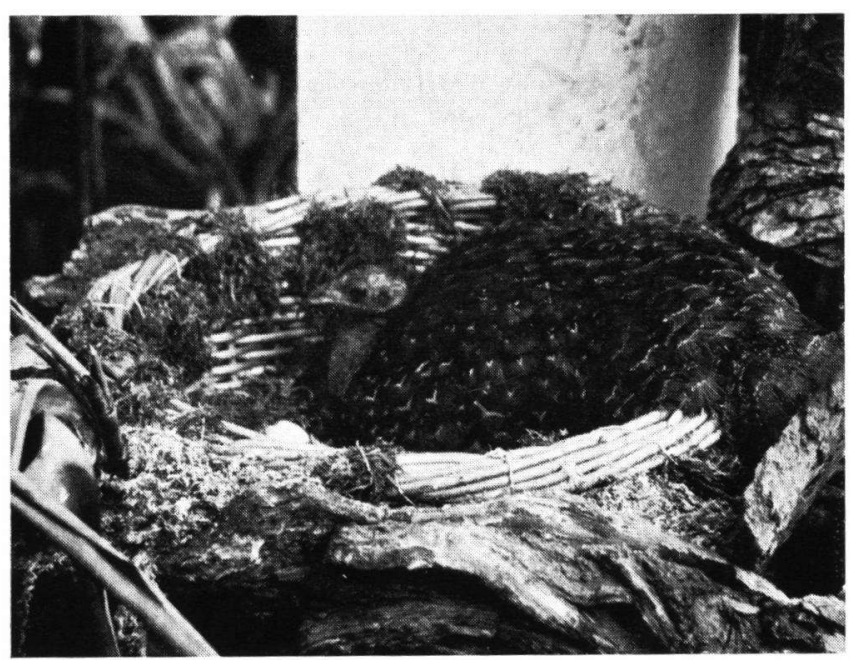

Female on nest. Day of hatching. Part of one of the eggs visible.

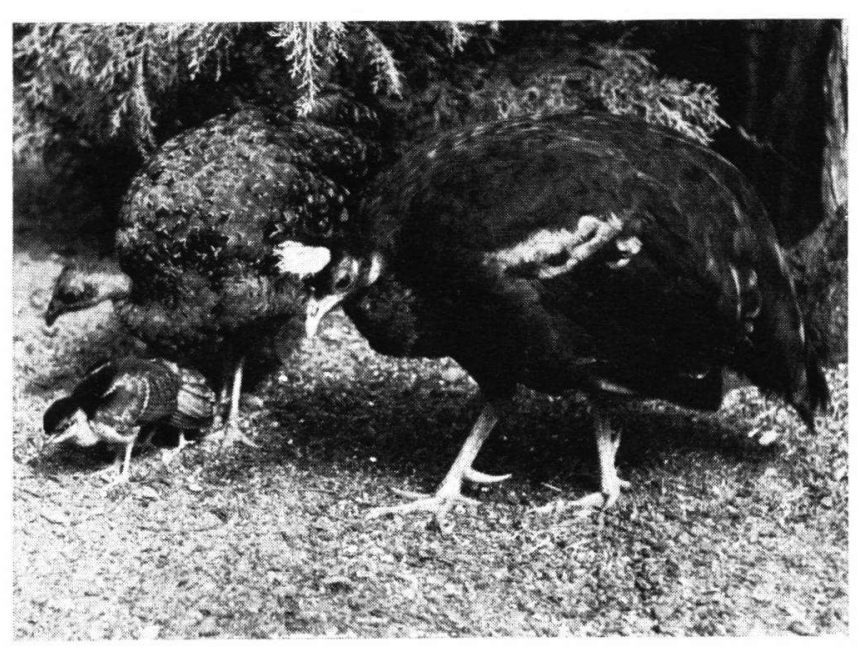

Parents with 10 days old chicks.

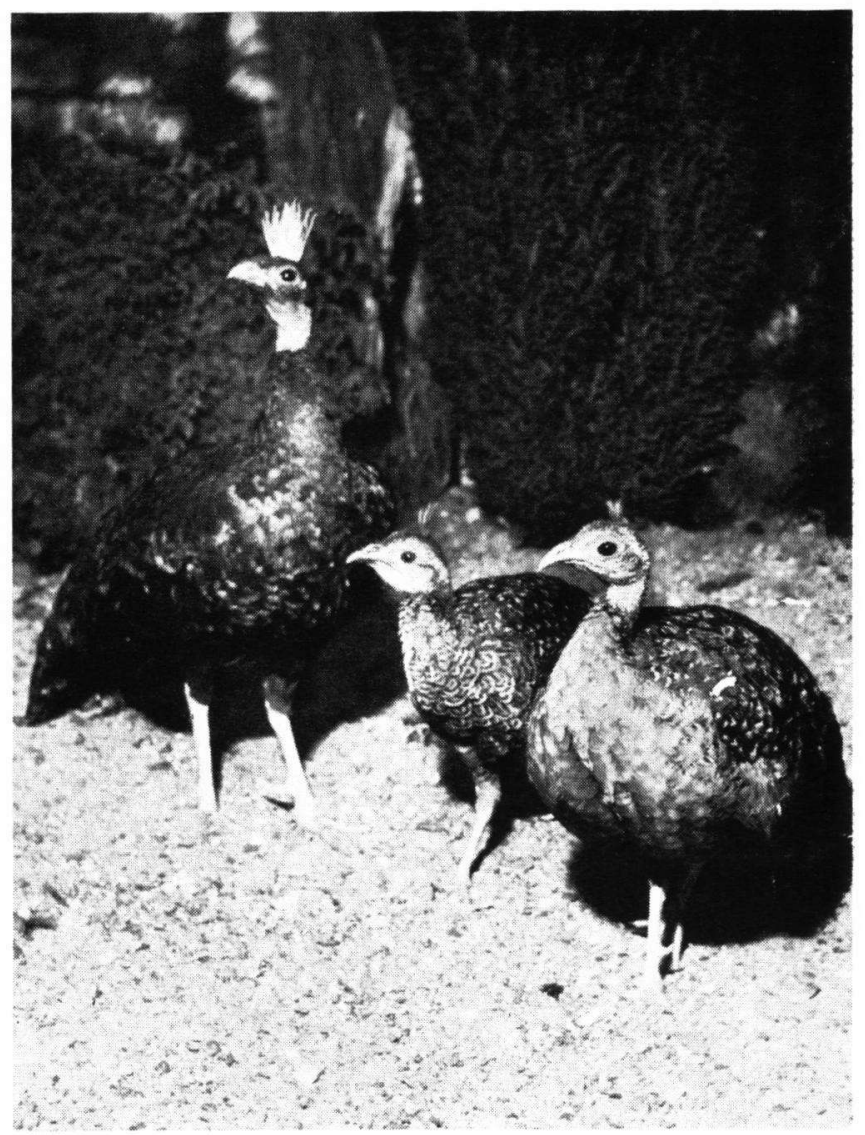

Parents with female chick, 6 month old. 
immature dress has been given by Delacour (9).

Some previous notes on this breedingcase have been published elsewhere $(1,2,3,10,11)$.

The breeding pair stayed together with the young hen till February 22d 1961. In the meantime the old birds started some sexual display at the end of January 1961. The young hen tried to interfere, sometimes harmlessly attacking the mother. If the old hen flew up to the nest, the young bird followed. The old hen laid an egg on February 17th, which was found broken. Two days later again a broken egg laid in the nest.

The director of the Royal Zoological Society Antwerpen had asked us to send our young bird to Kopenhagen, to try to make a pair with the single cock there. This seemed to be the right thing to do, also because the young bird had to be separated from the parents, interfering as she did with the breeding activities of the old birds. We had planned to send her earlier, but as she proved to be slightly infected with Capillaria, we treated her beforehand with dithiazamine $20 \mathrm{mg}$ daily. This had such good results that we thought we could bring her to Kopenhagen without any risks.

The three birds were very tame, eating from their keepers hand. So it was easy to catch the young bird, half an hour before leaving. We had not expected that the old cock would attack his keeper in this case as fiercely as he did. Five hours after putting the young bird in her box she was set free again in Kopenhagen Zoo, in a large aviary in the beautiful quarantaine. It was offered plenty of cover, water and food in the vicinity of the cover and everything seemed to be arranged very well. Alas, the bird, so tame in Rotterdam, was as shy as a newcaught bird. She refused any food, everything that was done, even putting the cock from Kopenhagen in an adjoining cage, could not bring her to feed, except a few mealworms which she took. She died after a week, much to our grief and to that of the staff of Kopenhagen Zoo, which had done everything to keep her alive.

A postmortem examination of the young hen proved aspergillosis to be the final cause of death. Now aspergillosis often appears in birds which are in bad condition, so most probably this can be considered to have originated from the weak condition of the young bird after the stress of displacement and the refusing of food for such a long time.
After this events, our good luck passed away. The old hen produced two eggs again on the 15th and 16th of April and started incubating immediately. After two weeks her condition decreased, due to a rapidly increasing infection with Capillaria. As the hen hardly took any food during the incubationperiod, it proved extremely difficult to make her take sufficient dithiazamine, which had given such good results formerly. On May 12th the hen left the nest. Both eggs being fertile, we put them in an incubator and on the 14th of May one chicken hatched. The other chicken died before hatching. During eight days we succeeded in keeping this chicken alive. It died from an intestinal stenose. After leaving the nest the old hen could be handled more easely and we administered a large dose of dithiazamine and extract of liver. This seemed to have a good result, but after four days the condition suddenly decreased and the hen died May 17th.

\section{SUMMARY OF RESULTS}

The incubation period of 26 days mentioned in literture $(3,9)$ seems to be a little short. Very probably it should be 27 or 28 days. Strong indications that Congo Peacock are nesting in trees were found. The clutch normally consists of 2 or 3 eggs. Other data about coloration of chicks and immature birds could be confirmed and completed. Some notes on behaviour in captivity could be made. A more complete study of ethiology should be made, but we had not the time necessary for accurate observations. It would be worth to make a careful comparison with the Peacock Pheasants.

\section{ACKNOWLEDGEMENTS}

Special thanks should go to Mr. W. van DEN BERGH, director of the Royal Zoological Society Antwerpen, who gave us the birds in trust. This is an example, of the attitude Zoo people should take in the case of rare and endangered species.

I think, in a work, dedicated to my good friend and sponsor Frits Appelman, the story of a most remarkable breeding case as that of the Congo Peacock should not be missed. Perhaps this was the most exciting thing in his whole career as a Zoo-man. Which, with so many exciting results, means quite something! 


\section{REFERENCES}

1. Appelman, F. J., 1961: The Congo Peacock, Avicultural Magazine 67, pt. 2, March-April.

2. Bemmet, A. C. V. van, 1961: Het is gelukt, Blijdorp Geluiden 9, pt. 3.

3. Bemmel, A. C. V. van, 1961: Kongopauwen, “Artis", July-August.

4. Chapin, J. P., 1942: The Congo Peacock in captivity, The Avicultural Magazine 5th Ser., pt. 4, July-Aug.

5. Chapn, J. P., 1948: How the Congo Peacock was discovered, Animal Kingdom 51, pt. 3, May-June.

6. Chapin, J. P., 1954: Birds of the Belgian Congo, Bull. Am. Mus. N.H. 75B, pt. 4.

7. Cordier, Ch., 1949: Further Adventures etc., Animal
Kingdom 52, pt. 1, January-Febr.

8. Corbier, CH., 1949: Our Belgian Congo Expedition comes home, Animal Kingdom 52, pt. 4, July-August.

9. Delacour, J., 1951: The Pheasants of the World, New York.

10. Doorn, C. van, 1961: Der Kongo Pfau, Freunde des Kölner Zoo 4, pt. 1.

11. Mark, R. R. P. van der, 1960: The first time Congo Peacocks have been raised in captivity, Game Bird Breeders Gazette, December.

12. VAN DEN BERGH, W. \& others, 1961: Het kweken in gevangenschap van Kongo-pauwen, Zoo (Antwerpen) 26 , pt. 3 , January. 